\title{
Resposta do quiabeiro às doses de fósforo aplicadas em solo arenoso
}

\author{
Ademar P. de Oliveira ${ }^{1}$; Carina Seixas M. Dornelas ${ }^{2}$; Adriana U. Alves²; Anarlete U. Alves ${ }^{3}$; Jandiê \\ Araújo da Silva²; Arnaldo Nonato P. de Oliveira ${ }^{3}$ \\ UFPB, CCA, C. Postal 02, 58397-000 Areia-PB ${ }^{1}$ Bolsista em produtividade em pesquisa CNPq; ${ }^{2}$ Programa de pós-graduação em \\ agronomia; ${ }^{3}$ Gaduação em agronomia; ademar@cca.ufpb.br
}

\section{RESUMO}

Avaliou-se o efeito da adubação fosfatada no rendimento do quiabeiro, cultivar Santa Cruz, em experimento com delineamento experimental de blocos casualizados, com cinco tratamentos $(0 ; 44$; 88; 132 e $176 \mathrm{~kg} \mathrm{ha}^{-1}$ de P), em quatro repetições. O número máximo de frutos por planta (43) foi obtido na dose máxima de $176 \mathrm{~kg}$ $\mathrm{ha}^{-1}$ de $\mathrm{P}$. A produtividade máxima estimada de frutos comerciais $\left(38,6\right.$ t ha $\left.^{-1}\right)$ ocorreu com $139 \mathrm{~kg} \mathrm{ha}^{-1}$ de P A dose de P que proporcionou maior retorno econômico foi $137 \mathrm{~kg} \mathrm{ha}^{-1}$, com produção de 38,3 $\mathrm{t} \mathrm{ha}^{-1}$ de frutos comerciais, o que representa um incremento de 17,4 t ha ${ }^{-1}$ de frutos. A dose mais econômica representou $98 \%$ daquela responsável pela máxima produção, o que pode indicar que o quiabeiro responde economicamente à adubação fosfatada no solo estudado e a dose de $\mathrm{P}$ responsável pela máxima produção comercial de frutos foi relacionada com $40 \mathrm{mg} \mathrm{dm}^{-3}$ de $\mathrm{P}$ disponível no solo (Mehlich 1). Da mesma forma, a dose responsável pelo maior retorno econômico foi associada com $38 \mathrm{mg}^{\mathrm{de}} \mathrm{P} \mathrm{dm}^{-3}$.

Palavras-chave: Abelmoschus esculentus, adubação fosfatada, Neossolo, retorno econômico.

\begin{abstract} soil

Response of phosphorus levels on okra planted in sandy

The influence of phosphorus fertilization on yield of okra, cv. Santa Cruz was evaluated. The research was carried out in the experimental design of randomized blocks, with five treatments $(0$; $44 ; 88 ; 132$ and $176 \mathrm{~kg} \mathrm{ha}^{-1}$ of $\mathrm{P}$ ), and four replications. The maximum number of fruits per plant (43) was obtained with the maximum level of $176 \mathrm{~kg} \mathrm{ha}^{-1}$ of P. The estimated maximum yield of commercial fruits $\left(38.6 \mathrm{tha}^{-1}\right)$, was related to $139 \mathrm{~kg} \mathrm{ha}^{-1}$ of P. The application of $137 \mathrm{~kg} \mathrm{ha}^{-1}$ of $\mathrm{P}$ provided the highest economical income, yielding $38.3 \mathrm{t} \mathrm{ha}^{-1}$ of commercial fruits, with an increment of fruits of $17.4 \mathrm{t}$ $\mathrm{ha}^{-1}$. The most economic level represented $98 \%$ of that responsible for the maximum yield, indicating that the okra responded economically to the use of $\mathrm{P}$ in sandy soil and, of the P level responsible for the maximum commercial yield of fruits were related to $40 \mathrm{mg} \mathrm{dm}^{-3}$ of available $\mathrm{P}$ in soil (Mehlich 1), and the level responsible for the highest economic income was related to $38 \mathrm{mg}$ $\mathrm{dm}^{-3}$.
\end{abstract}

Keywords: Abelmoschus esculentus, phosphated fertilization, Quartz psamment, economic income.

\section{(Recebido para publicação em 15 de dezembro de 2005; aceito em 12 de junho de 2007)}

A adubação mineral é uma das práticas que mais afeta a produção de hortaliças, tanto sob o aspecto tecnológico quanto econômico (Filgueira, 2000). As doses de fertilizantes aplicadas no solo não devem ser limitantes ao crescimento e à produtividade das culturas, no entanto, se em excesso, poderão interferir na absorção de outros nutrientes (Coutinho et al.,1993).

O fósforo, geralmente, é um nutriente limitante da produção agrícola nos solos tropicais e subtropicais, devido aos seus baixos teores no solo, fato que implica na prática constante da adubação fosfatada (Minhoni et al., 1991). O fósforo atua positivamente no florescimento e na frutificação das plantas, contribui para o bom desenvolvimento do sistema radicular e incrementa a produção, melhorando a qualidade dos produtos vegetais (Raij, 1991). Apesar das plantas requererem menor quanti- dade desse nutriente, em relação ao potássio e nitrogênio, as recomendações, para a adubação das culturas indicam quantidades de fósforo superiores às daqueles nutrientes, devido ao seu baixo aproveitamento (5\% a 20\%), em decorrência do fenômeno da fixação, que resulta na redução da disponibilidade em solos tropicais (Alcarde et al., 1989; Vale et al., 1993).

Em solos naturalmente bem supridos em fósforo, a sua adição não afeta a produção nem a qualidade das hortaliças (Fontes \& Wilcox, 1984). Contudo, mesmo em solos já adubados anteriormente, em geral, a deficiência de fósforo poderá ocorrer, sendo possível obter curva de respostas para as diferentes classes de teores desse nutriente no solo (Raij, 1991). Os solos, porém, diferem quanto à imobilização dos fosfatos e as condições que favorecem a intensidade deste fenômeno são maior teor de argila e de óxidos de ferro e alumínio nessa fração, e menor valor de pH (Raij, 1983). Em condições de solos com pequena CMAP (Capacidade Máxima de Adsorção de P), como os arenosos, é preciso maior valor do I (Fator Intensidade), ou seja, a concentração ótima para atender à demanda da planta; bem como para uma mesma quantidade de fósforo colocada no solo, devem ser encontrados valores do I bem maiores nos solos arenosos (Novais \& Smyth, 1999).

As culturas absorvem fósforo desde os primeiros estádios de crescimento, durante a germinação e a emergência e, daí por diante, até a senescência. $\mathrm{O}$ fósforo é, reconhecidamente, um nutriente relevante para a obtenção de produtividade elevada. Tem sido o macronutriente que freqüentemente limita a produção, e apesar da pequena exigência da cultura são obtidas respostas positivas à adubação fosfatada. Além da pobreza dos solos brasileiros em fós- 
foro disponível, é baixo o aproveitamento desse nutriente aplicado via adubação, pois sua retenção é elevada nos solos tropicais (Novais \& Smith, 1999).

Embora o fósforo seja um dos nutrientes que proporcione maior resposta em termos de produção de frutos no quiabeiro (Filgueira, 2000), pouco se conhece, ainda, a respeito das quantidades a serem utilizadas, permitindo rendimentos satisfatórios nessa cultura. As recomendações do seu emprego para essa hortaliça encontradas na literatura variam de $96 \mathrm{~kg} \mathrm{ha}^{-1}$ de $\mathrm{P}$ para a região do Amazonas (Pimentel, 1985), até 152 $\mathrm{kg} \mathrm{ha}^{-1}$ de $\mathrm{P}$ para solos de fertilidade média ou baixa nas regiões Sul e Sudeste do país (Filgueira, 2000). Este trabalho teve como objetivo avaliar a reposta do quiabeiro às doses de fósforo aplicadas em solo arenoso.

\section{MATERIAL E MÉTODOS}

O trabalho foi conduzido em área experimental da UFPB, em Areia, entre outubro de 2004 e fevereiro de 2005, em solo NEOSSOLO REGOLÍTICO Psamítico Típico (Embrapa, 1999), textura areia franca. As análises químicas e físicas da camada de 0-20 cm, realizadas segundo Embrapa (1997), resultaram em: $\mathrm{pH}=6,4$; $\mathrm{P}=11,24 \mathrm{mg} \mathrm{dm}^{-3} ; \mathrm{K}=217,25 \mathrm{mg} \mathrm{dm}^{-3}$; $\mathrm{Al}^{+3}=0,05 \mathrm{cmol}_{\mathrm{c}} \mathrm{dm}^{-3} ; \mathrm{Ca}^{2+}=4,95 \mathrm{cmol}$ $\mathrm{dm}^{-3} ; \mathrm{Mg}^{2+}=2,5^{\mathrm{c}} \mathrm{cmol}_{\mathrm{c}} \mathrm{dm}^{-3}$; matéria orgânica $=24,93 \mathrm{~g} \mathrm{~kg}^{-1}$; areia grossa $=672$ $\mathrm{g} \mathrm{kg}^{-1}$; areia fina $=125 \mathrm{~g} \mathrm{~kg}^{-1} ;$ silte $=126 \mathrm{~g}$ $\mathrm{kg}^{-1}$; argila $=77 \mathrm{~g} \mathrm{~kg}^{-1}$ e densidade do solo $=1,28 \mathrm{~g} \mathrm{~cm}^{-3}$. O preparo do solo foi realizado com aração e gradagem, em seguida foram abertas as covas de plantio.

Utilizou-se o delineamento experimental de blocos casualizados com cinco tratamentos $(0 ; 44 ; 88 ; 132$ e $136 \mathrm{~kg}$ $\mathrm{ha}^{-1}$ de P) e quatro repetições. As parcelas mediram $20 \mathrm{~m}^{2}$, com 40 plantas espaçadas de $1,0 \mathrm{~m}$ entre fileiras e $0,50 \mathrm{~m}$ entre plantas, sendo consideradas nas avaliações as 20 plantas centrais, com área útil de $10 \mathrm{~m}^{2}$. O plantio da cultura foi realizado por meio de semeadura direta, colocando-se quatro sementes por cova da cultivar Santa Cruz. O desbaste foi feito quinze dias após a semeadura, deixando-se duas plantas por cova.

A adubação de plantio consistiu da aplicação nas covas das doses de $\mathrm{P}_{2} \mathrm{O}_{5}$, utilizando-se como fonte o superfosfato triplo e de $20 \mathrm{t} \mathrm{ha}^{-1}$ de esterco bovino. A adubação de cobertura constou da aplicação de $120 \mathrm{~kg} \mathrm{ha}^{-1}$ de N, utilizando-se como fonte o sulfato de amônio e $40 \mathrm{~kg}$ $\mathrm{ha}^{-1}$ de $\mathrm{K}$, utilizando como fonte o cloreto de potássio, parcelados em quantidade iguais, aos 30, 60 e 90 dias após a semeadura.

Realizaram-se os tratos culturais normais para a cultura, incluindo irrigação por aspersão, com turno de rega de três vezes por semana, procurando fornecer quantidade de água suficiente para o bom desenvolvimento da cultura nos períodos de ausência de precipitação; capinas com auxílio de enxadas para manter a cultura sempre livre de plantas invasoras, e pulverizações à base de Benomyl (20 ml/20 L de $\mathrm{H}_{2} \mathrm{O}$ ), para controlar a ocorrência de oídio (Erysiphe polygoni).

As colheitas foram efetuadas a cada dois dias, no período de 70 a 170 dias após a semeadura, quando os frutos apresentaram coloração verde intensa. Os frutos colhidos foram transportados para um galpão, com o objetivo de se avaliar o número de frutos por planta $\mathrm{e}$ sua produtividade comercial. Ao final da colheita efetuou-se a amostragem do solo (0 - $20 \mathrm{~cm}$ de profundidade), coletando-se dez amostras simples ao acaso por parcela, as quais originaram uma amostra composta para se determinar as concentrações de $\mathrm{P}$ disponível pelo extrator Mehlich 1, em função das suas doses aplicadas.

Os resultados obtidos foram submetidos à análise de variância e de regressão polinomial, utilizando-se o "software" Saeg (2000). Na análise de regressão, foram testados os modelos linear, quadrático e cúbico, sendo selecionados para expressar o comportamento das doses de P sobre as características avaliadas, aquele que apresentou o maior valor para o coeficiente de determinação $\left(\mathrm{R}^{2}\right)$. Também foi determinada a dose $\mathrm{P}$ capaz de promover o maior retorno econômico para a produção de frutos comerciais, conforme Raij (1991). Os valores utilizados para as variáveis frutos comerciais e $\mathrm{P}$, vigentes em Areia-PB em janeiro de 2005 foram: $\mathrm{R} \$ 0,50 / \mathrm{kg}$ de frutos e de $\mathrm{R} \$$ $1,72 / \mathrm{kg}$ de $\mathrm{P}$, ressaltando porém, que essa relação de preço pode variar a cada ano, conforme a demanda e oferta. No entanto, a fim de atenuar os problemas de variação cambial, trabalhou-se com uma relação de troca ao invés de moeda corrente (Natale et al., 1996), procurando-se assim dados mais estáveis. Portanto, a "moeda" utilizada nos cálculos, foi o próprio fruto, considerando-se a seguinte relação de equivalência: quilograma de $\mathrm{P} / \mathrm{kg}$ de frutos igual a 3,5, sendo a dose mais econômica calculada com base na derivada da equação de regressão entre a produções de frutos e as doses de $\mathrm{P}$ por meio da relação de $d y / d x=a_{1}+2 a_{2} x$. A doses mais econômica ( $x$ ' ) foi então calculada por:

$$
x^{\prime}=\frac{a_{1}-\text { relação de equivalência }}{2\left(-a_{2}\right)}
$$

Onde $\mathbf{x}$ ' representa a dose econômica, $\mathbf{a}_{\mathbf{1}}$ a taxa de incremento de produção e $\mathbf{a}_{2}$, o ponto de máxima produção.

\section{RESULTADOS E DISCUSSÃO}

Houve efeito significativo $(\mathrm{P}<0,05)$ das doses de $\mathrm{P}$ empregadas para todas as características avaliadas.

$\mathrm{O}$ número de frutos por planta aumentou de forma linear à medida que as doses de $\mathrm{P}$ foram aumentadas. O valor mais elevado para o número de frutos por planta (43), no intervalo de estudo, foi obtido com a aplicação da dose máxima de $\mathrm{P}$ (176 kg ha-1) (Figura 1). Este resultado indica que o ponto de máximo não foi atingido nas condições do experimento. Em feijão-vagem, Oliveira et al. (2005) testando doses de $\mathrm{P}$ variando de 0 a $176 \mathrm{~kg} \mathrm{ha}^{-1} \mathrm{em}$ solo arenoso com 11,06 $\mathrm{mg} \mathrm{dm}^{-3}$ de $\mathrm{P}$ disponível, obtiveram número máximo de frutos na dose de $116 \mathrm{~kg} \mathrm{ha}^{-1}$. Em pepino, Silva et al. (2003) avaliando diferentes fontes solúveis de fósforo na fertirrigação por gotejamento, em solo de textura média, verificaram elevação do número de frutos por planta com aplicação de $262 \mathrm{~kg} \mathrm{ha}^{-1}$ de $\mathrm{P}$.

As médias da produtividade comercial de frutos se ajustaram ao modelo quadrático de regressão (Figura 2), onde pela derivada da equação, calculou-se a 


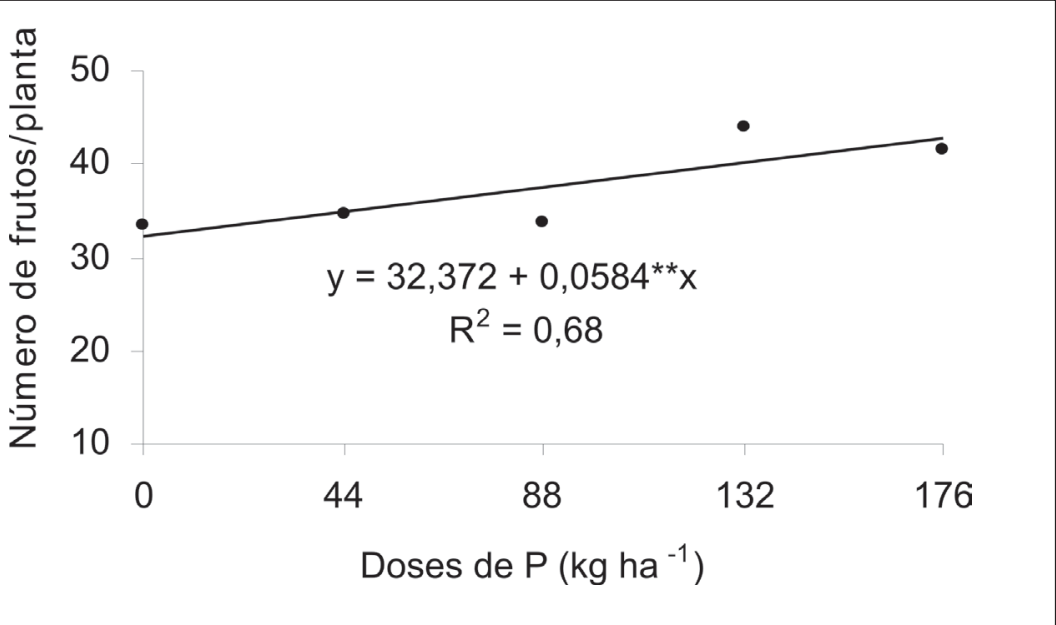

Figura 1. Número de frutos/planta de quiabeiro em função de doses de P. (Number of fruits per plant of okra depending on P levels). Areia, CCA-UFPB, 2005.

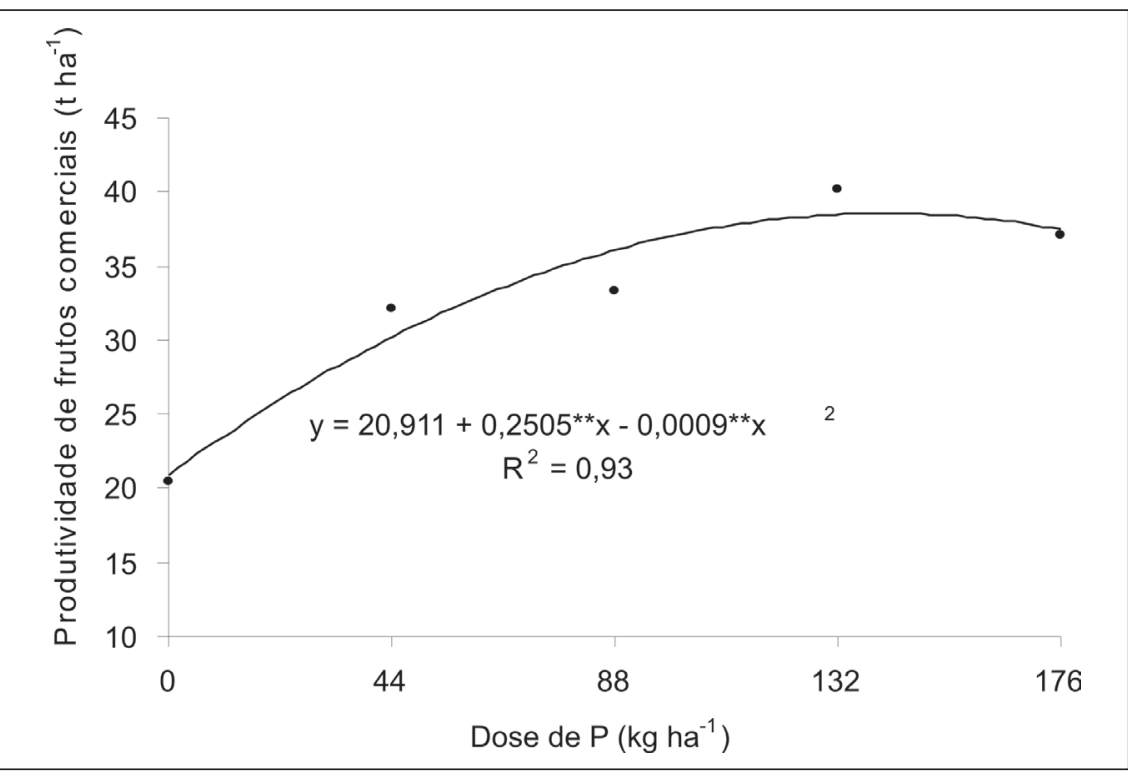

Figura 2. Produtividade de frutos comerciais de quiabeiro em função de doses de P. (Yield of commercial fruits of okra fertilized with P levels). Areia, CCA-UFPB, 2005.

dose de $139 \mathrm{~kg} \mathrm{ha}^{-1}$ de $\mathrm{P}$, como aquela responsável pela produtividade máxima estimada de $38,6 \mathrm{~kg} \mathrm{ha}^{-1}$ de frutos. Esses resultados evidenciam uma adequada perspectiva de produção de frutos no quiabeiro na microrregião de Areia, em decorrência da produtividade máxima de frutos comerciais ter se enquadrado dentro da média nacional relatada por Filgueira (2000), na faixa de 20 a $40 \mathrm{t}$ $\mathrm{ha}^{-1}$ de frutos comerciais.

A aplicação de doses adequadas de $\mathrm{P}$ é eficiente para se aumentar a produção de frutos em hortaliças, porque seu fornecimento às culturas oleráceas favorece o desenvolvimento do sistema radicular e aumenta a absorção de água e nutrientes, estimulando a floração e a frutificação (Filgueira, 2000). Portanto, durante o crescimento e desenvolvimento das plantas, a dose de $\mathrm{P}$ responsável pela máxima produção comercial de frutos, supriu de forma equilibrada as necessidades do quiabeiro, em relação ao referido nutriente. Dwivedi et al. (1993), Faraq \& Damrany (1994) e Anjum \& Amjad (1999), em solos de textura média, estudando efeito de doses de $\mathrm{P}$ entre 60 e $150 \mathrm{~kg} \mathrm{ha}^{-1}$, obtiveram aumento de produtividade de frutos comerciais de quiabeiro com aplicação de 100 $\mathrm{kg} \mathrm{ha}^{-1}$ de P. Silva et al. (2001), estu- dando a resposta do tomateiro à doses de $\mathrm{P}$ variando de 88 a $262 \mathrm{~kg} \mathrm{ha}^{-1}$, em solo com $22 \mathrm{~g} \mathrm{~kg}^{-1}$ de Areia e $24 \mathrm{~g} \mathrm{~kg}^{-1}$ de argila, obtiveram elevação na produtividade de frutos comerciais de tomate em função do fornecimento de dose adequada de P (262 kg ha-1). Amjad et al. (2002), avaliando as doses de 73; 87 e $104 \mathrm{~kg} \mathrm{ha}^{-1}$ de $\mathrm{P}$, em solo de textura média, verificaram redução da produtividade de frutos de quiabeiro em doses acima cima de $87 \mathrm{~kg} \mathrm{ha}^{-1}$.

A dose de $\mathrm{P}$ capaz de proporcionar maior retorno econômico para a produtividade de frutos, determinada pela fórmula: $(250$ - 3,5)/(2 x 0,09) foi de 137 $\mathrm{kg} \mathrm{ha}^{-1}$, com produção de $8,3 \mathrm{t} \mathrm{ha}^{-1}$ de frutos comerciais, o que representa um incremento de 17,4 $\mathrm{t} \mathrm{ha}^{-1}$ de frutos, em relação à ausência do insumo. Essa dose representou $98 \%$ daquela responsável pela máxima produção indicando que o quiabeiro responde economicamente ao emprego de fósforo já que, conforme Lobato (1982), a melhor eficiência econômica para esse nutriente encontra-se entre 80 e $98 \%$ da produção máxima.

As doses de $\mathrm{P}$ obtidas para máxima produtividade comercial de frutos e maior retorno econômico correlacionaram-se com 40 e $38 \mathrm{mg} \mathrm{dm}^{-3}$ de $\mathrm{P}$ disponível (Mehlich 1), respectivamente (Figura 3). Portanto, a probabilidade de ocorrência de resposta do quiabeiro à adubação fosfatada, em solos semelhantes ao do presente estudo, será minimizada quando o teor de $\mathrm{P}$ disponível for superior a $40 \mathrm{mg} \mathrm{dm}^{-3}$.

Independentemente do tipo de solo, Pimentel (1985) recomenda para a fertilização do quiabeiro a aplicação de 88 $\mathrm{kg} \mathrm{ha}^{-1}$ de $\mathrm{P}$, para as condições da região Norte. Blanco et al. (1997) recomendam $175 \mathrm{~kg} \mathrm{ha}^{-1}$ para as condições do estado de São Paulo e Filgueira (2000) recomenda $153 \mathrm{~kg} \mathrm{ha}^{-1}$ para as condições das regiões Sul e Sudeste. As doses responsáveis pela máxima produção de frutos comerciais e eficiência econômica nas condições de clima e solo do experimento, situam-se na faixa daquelas recomendadas pelos autores.

O baixo nível de P no solo, conforme Novais \& Smyth (1999), pode ter sido responsável pela resposta positiva de todas as características avaliadas ao emprego do $\mathrm{P}$, indicando que nas con- 
dições regionais de Areia, para o estabelecimento da cultura do quiabeiro em Neossolo Regolítico Psamítico Típico, textura franca, com características químicas semelhantes ao solo onde o trabalho foi conduzido, é recomendável a aplicação de $137 \mathrm{~kg} \mathrm{ha}^{-1}$ de P.

Considerando-se que o teor de fósforo disponível (extrator Mehlich 1) inicialmente foi interpretado como baixo, os resultados obtidos refletem a importância da adubação fosfatada na cultura do quiabeiro, com melhoria no rendimento de frutos.

\section{REFERÊNCIAS}

ALCARDE JC; GUIDOLIN JA; LOPES AS 1989. Aos adubos e a eficiência das adubações. São Paulo: ANDA, 35p. (ANDA. Boletim Técnico, 3).

AMJAD M; SULTAN M; MUHAMMAD AKBAR ANJUM MA; AYYUB CM. 2002. Response of okra (Abelmoschus esculentus) to various doses of $\mathrm{N}$ and $\mathrm{P}$ and different plant spacings. Journal of Research Science 13: 19-29.

ANJUM MA; AMJAD M. 1999. Response of okra (Abelmoschus esculentus L. Moench) to different levels of $\mathrm{N}, \mathrm{P}$ and $\mathrm{K}$ fertilizers, Journal Biology. Science 1: 794-796.

BLANCO MCSG; GROPPO GA; TESSARIOLI NETO J. 1997. Feijão-vagem ( Phaseolus vulgaris L. ). In: Manual Técnico da Culturas, Campinas (SP), 8: 63-65, $2^{\mathrm{a}}$ ed.

COUTINHO ELM; NATALE W; SOUZA ECA. 1993. Adubos e corretivos: aspectos particulares na olericultura. In: Ferreira ME: CASTELLANE PD; CRUZ MCP. (eds). Nutrição e adubação de hortaliças. Piracicaba: POTAFÓS, p.85-140

DWIVEDI YC; SENGUPTA SK; NAIDU AK; CHOUBEY PC. 1993. Effect of $\mathrm{N}$ and P on growth and seed yield of okra. JNKVV journal Research 3: 53-55.

EMBRAPA. Serviço Nacional de Levantamento e Conservação do Solo. 1997. Manual de métodos de análise de solo. Rio de Janeiro: Ministério da Agricultura, 212 p.

EMBRAPA. 1999. Centro Nacional de Pesquisa de Solos. Sistema Brasileiro de Classificação de Solos. Brasília: Produções de Informações, 412 p.

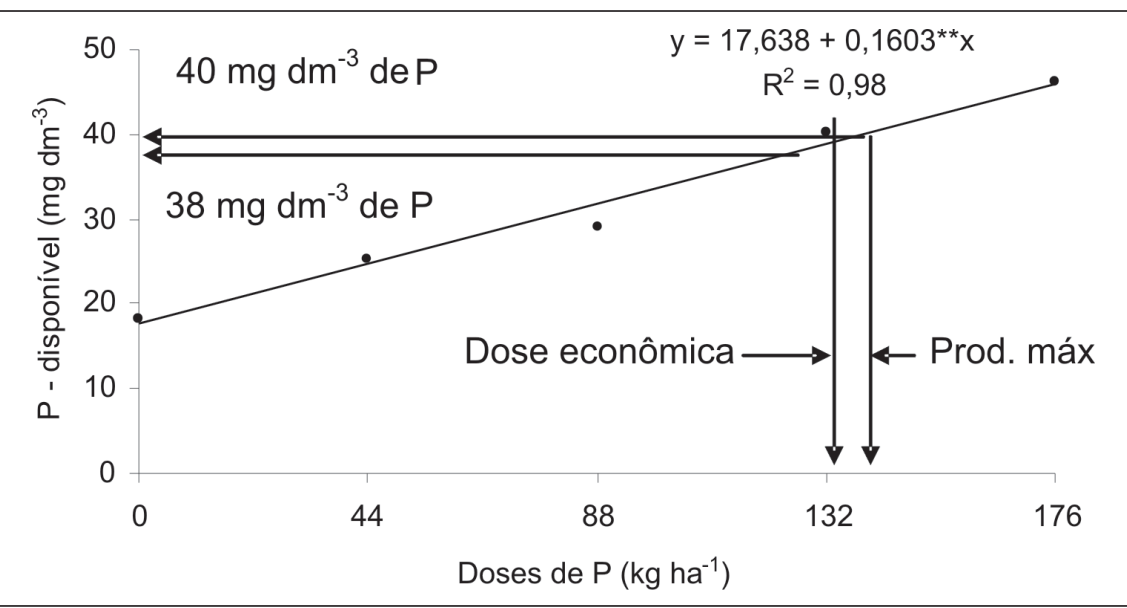

Figura 3. Teores de P - disponível (Melich - 1), em função de doses de P para estabelecimento de quiabeiro em NEOSSOLO REGOLÍTICO Psamítico Típico textura franca. (Disponible P in soil (Mehlich - 1) as a function of P levels in the okra establishment in Quartz psamment). Areia, UFPB, 2005.

FARAQ IA; DAMRANY AM. 1994. The response of two okra cultivars to NPK levels and spacing on growth, yield and quality. Assiut Journal Agricola. Science 25: 99-117.

FILGUEIRA FAR. 2000. Novo manual de olericultura: agrotecnologia moderna na produção e comercialização de hortaliças, Viçosa: ed. UFV, 402p.

FONTES PCR; WILCOX GE. 1984. Growth and phosphorus uptake by tomato cultivars as influenced by phosphorus concentration in soil and nutrient solution. Journal of the American Society for Horticultural Science 109: 633636.

LOBATO E. 1982. Adubação fosfatada em solos da Regiõa Centro-Oeste. In: OLIVEIRA AJ; LIURENÇO S; GOEDERT WJ. Adubação fosfatada no Brasil. Brasília: EMBRAPADID, 209 p. (EMBRAPA - DID. Documento 21)

MINHONI MTA; CARDOSO EJBN; EIRA AF 1991. Efeito de cinco tipos de matéria orgânica na solubilização microbiana de fosfato de rocha. Revista Brasileira de Ciência do Solo 15: 29-35.

NATALE W; COUTINHO ELM; BOARETTO A; PEREIRA FM. 1996. Dose mais econômica de adubo nitrogenado para a goiabeira em formação. Horticultura Brasileira 14: 196-199.
NOVAIS RF; SMYTH TJ. 1999. Fósforo em solo e planta em condições tropicais. Viçosa: UFV, DPS, 399 p.

OLIVEIRA AP; CARDOSO MMO; BARBOSA LJN; SILVA JEL; MORAIS MS. 2005. Resposta do feijão-vagem a $\mathrm{P}_{2} \mathrm{O}_{5}$ em solo arenoso com baixo teor de fósforo. Horticultura Brasileira 23: 128-132.

PIMENTEL AAMP. 1985. Olericultura no Trópico úmido. São Paulo: Agronômica Ceres, 321 p.

RAIJ BV. 1983. Avaliação da fertilidade do solo. 2. ed. Piracicaba: Instituto da Potassa \& Fosfato, 142p.

RAIJ BV. 1991. Fertilidade do solo e adubação. Piracicaba: Ceres/Potafos, 343p.

SAEG - Sistema para análise estatística, versão 8.0. 2000. Viçosa-MG: Fundação Arthur Bernardes.

SILVA HR; CARRIJO OA; MAROUELLI WA; OLIVEIRA CAS. 2003. Avaliação de fontes de $\mathrm{P}$ na fertirrigação da cultura do pepino sob cultivo protegido.In: CONGRESSO BRASILEIRO DE OLERICULTURA, 43., 2003, Recife. Resumos... Recife: SOB.

VALE FR; GUILHERME LRG; GUEDES GAA. 1993. Fertilidade do solo: dinâmica e disponibilidade dos nutrientes de plantas. Lavras: ESAL, $171 \mathrm{p}$. 